\title{
Evaluation of fracture toughness and impact toughness of laser rapid manufactured Inconel-625 structures and their co-relation
}

\author{
Ganesh Puppala, ${ }^{1, *}$, Aniruddha Moitra ${ }^{2}$, S. Sathyanarayanan ${ }^{2}$, Rakesh Kaul ${ }^{1}$, \\ Sasikala $G^{2}$, $\underline{\text { Ram Chandra Prasad }}{ }^{3}$, Lalit. M. Kukreja ${ }^{1}$ \\ ${ }^{1}$ Raja Ramanna Centre for Advanced Technology, Indore 452013, India \\ ${ }^{2}$ Indira Gandhi Centre for Atomic Research, Kalpakkam 603102, India \\ ${ }^{3}$ Metallurgical Engg. \& Materials Science Department, Indian Institute of Technology Bombay, Mumbai, 400076, India \\ * Corresponding author: puppala.ganesh@gmail.com
}

\begin{abstract}
The present study involves evaluation of fracture toughness (crack tip opening displacement) and Chapry impact toughness of Inconel 625 structures fabricated by laser based additive manufacturing. The results of fracture toughness are close to those reported for the Inconel 625 weld metal. The nature of the load-time traces of instrumented Charpy impact tests revealed that the alloy Inconel 625 in laser fabricated condition was associated with fully ductile behavior with Charpy-V notch impact energy in the range of 48$54 \mathrm{~J}$. Stress relieving heat treatment at $950{ }^{\circ} \mathrm{C}$ for 1 hour has resulted in marginal improvement in the impact toughness by about $10 \%$, whereas no clear evidence of such improvement is seen in the CTOD fracture toughness. Fractographic examination of the Chapry specimens and the results of the instrumented impact tests imply that the mechanism of crack growth was propagation controlled under dynamic loading conditions. Dynamic fracture parameters were estimated from the instrumented impact test data and compared with the experimentally evaluated fracture toughness results.
\end{abstract}

Keywords: Laser rapid manufacturing, Inconel-625, CTOD fracture toughness, Instrumented impact test.

\section{Introduction}

With increasing competition due to global economy, manufacturers face challenge to deliver products with new design and maximum possible features in a short time frame, to meet increasing market demands. This led to the development of various time-compression technologies, including Laminated Object Manufacturing (LOM), Selective Laser Sintering (SLS), Laser Rapid Manufacturing (also known as Laser Engineered Net Shaping (LENS), Direct Metal Deposition (DMD), Automated Light Fabrication (ALF) and Solid Freeform Fabrication (SFF)) etc. [1-8]. Laser rapid manufacturing (LRM) is an emerging computer aided manufacturing methodology that employs a high power laser beam to deposit clad layer and build up three-dimensional component in a layer-by layer fashion [8]. Unlike conventional machining based manufacturing processes, LRM is additive in nature and has potential to directly fabricate functional metal parts with complex geometry and can also be used to add intricate features to existing components with short turnaround time. Due to its attractive attributes LRM forms an active area of research with different names at various laboratories around the world. Related literature in this area is focused on process development, its viability for specific end applications, parameter standardization for controlling structural features and mechanical properties of resultant structures [2-6]. Paul et al have reported optimization of process parameters for LRM of Inconel 625 (IN-625) structures [9]. On the other hand, related studies by Dinda et al [5] and Xue et al [10] have reported micro-structural and mechanical property characteristics of laser deposited structures of Inconel 625. Fatigue and fracture toughness are very important characteristics influencing safe life operation of engineering components. There are a few published reports on fatigue and fracture toughness characterization of Laser Rapid Manufactured (LRMed) structures. Blackwell and Wisbey [2] 
reported tensile strength and fracture toughness of Ti-6Al-4V alloy structures fabricated by LENS process. Xeu et al have reported that presence of unmelted/partially melted particles adversely affect fatigue life of LENS-processed structures [11]. Theriault et al studied uni-axial fatigue behavior of laser consolidated IN-625 structure at room and elevated temperatures [12]. A recent study performed in authors' laboratory has evaluated initiation fracture toughness $\left(\mathrm{J}_{0.2}\right)$ and compared fatigue crack growth rate (FCGR) in laser rapid manufactured (LRMed) structure of IN-625 with that reported for its wrought counterpart [8]. In an extension to this work, present investigations aims to evaluate the critical Crack Tip Opening Displacement (CTOD) fracture toughness and to study fracture behavior of laser rapid manufactured structures of alloy IN-625 under dynamic loading condition using instrumented charpy impact tests.

\subsection{Experimental}

\subsection{Material investigated}

Inconel 625 is a nickel-based superalloy stiffened by solid-solution strengthening of Ni-Cr matrix by refractory metals like, $\mathrm{Nb}$ and Mo. The alloy displays excellent resistance to a wide range of corrosive environments of unusual severity as well as to high-temperature effects like oxidation and carburization. High resistance of the alloy against localized corrosion, corrosion-fatigue and stress corrosion cracking (in chloride ion environment), along with high tensile strength, makes it an excellent choice for sea-water applications. Due to its good weldability and high oxidation resistance, IN-625 is an attractive material for aerospace applications, including aircraft ventilation systems, engine exhaust systems etc. The choice of IN-625 for the present study is because of its high temperature oxidation resistance, good mechanical strength and wide use in high temperature applications $[4,5,10,13]$.

Table-1: Chemical composition (weight \%) of the Inconel 625 alloy powder.

\begin{tabular}{|c|c||c|c||c|c|c|c||c|}
\hline $\mathrm{C}$ & $\mathrm{Cr}$ & $\mathrm{Ni}$ & $\mathrm{Si}$ & $\mathrm{Mo}$ & $\mathrm{Fe}$ & $\mathrm{Ti}$ & $\mathrm{Al}$ & $\mathrm{Nb}$ \\
\hline 0.1 & 22.5 & 58.6 & 0.5 & 9.2 & 4.7 & 0.36 & 0.4 & 3.6 \\
\hline
\end{tabular}

Table-2: Experimental parameters used for Laser Rapid Manufacturing

\begin{tabular}{|c|c|c|c|c|c|}
\hline Laser power & Track width & Scan rate & Powder feed rate & Track overlap & Gas flow rate \\
\hline $2.8-3 \mathrm{~kW}$ & $3 \mathrm{~mm}$ & $6.7-8.3 \mathrm{~mm} / \mathrm{s}$ & $6-8 \mathrm{gm} / \mathrm{min}$ & $50 \%$ & $12 \mathrm{lpm}$ \\
\hline
\end{tabular}

\subsection{Experimental setup for LRM of Inconel 625 specimens}

The experimental LRM setup comprised of an in-house developed $3.5 \mathrm{~kW}$ continuous wave $\mathrm{CO}_{2}$ laser $[14,15]$, integrated with a beam delivery system, co-axial powder-feeding system and a 3axis CNC work station. The raw laser beam, emanating out of the laser system, was folded with a $45^{\circ}$ water-cooled gold-coated plane copper mirror and the folded laser beam was subsequently focused with a $\mathrm{ZnSe}$ lens of $127 \mathrm{~mm}$ focal length, housed in a water-cooled co-axial copper nozzle. Laser rapid manufacturing involved scanning of the substrate/partly formed structure with a defocused laser beam of about $3 \mathrm{~mm}$ diameter along with simultaneous injection of IN-625 alloy powder (particle size: 45 - $106 \mu \mathrm{m}$ ) through a co-axial powder feeder into the resultant molten pool. During the course of LRM, argon gas was blown through the nozzle to protect the ZnSe optics from possible particulate spatter as well as to shield the molten pool from ambient contamination and 
oxidation. Multi-layer over-lapping clad tracks were deposited to build-up the desired volume. Laser processing parameters were optimized for obtaining metallurgically sound clad deposits free of interlayer defects and cracks [9]. Under optimized experimental parameters, built-up height of each layer was $1.0 \pm 0.2 \mathrm{~mm}$ with about $80 \%$ powder catchment efficiency. Average deposition rate was in the range $350-400 \mathrm{~g} / \mathrm{hr}$. Tables 1 and 2 present chemical composition of IN-625 alloy powder (in weight \%) and experimental LRM parameters, respectively. During the course of LRM, temperature of laser interaction zone was measured (with a dual wavelength infrared thermometer) and maintained in the range of $1500-1600^{\circ} \mathrm{C}$ (melting temperature range of IN-625 $=1290-1350{ }^{\circ} \mathrm{C}$ ) which produced defect-free clad tracks.

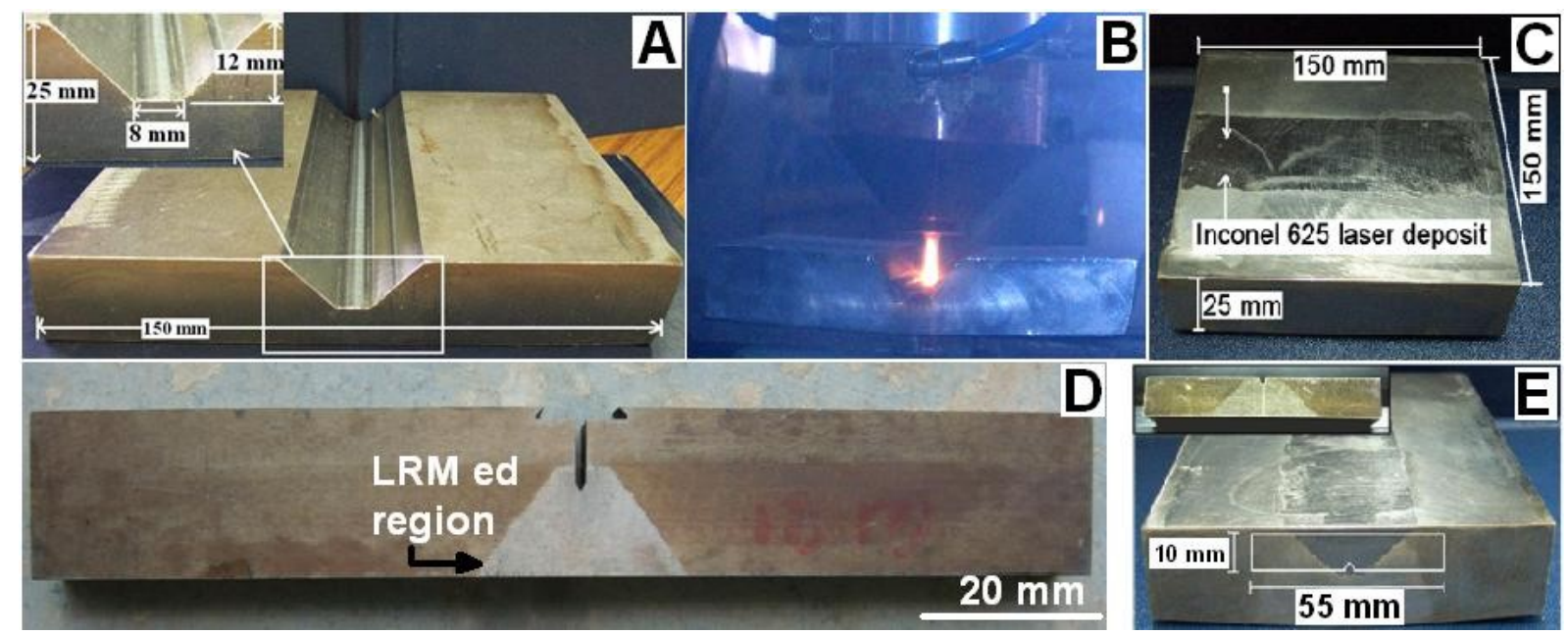

Figure 1: Various stages of specimen preparation - (A) V-grooved stainless steel block used for laser deposition; (B) laser deposition of IN-625 in V-grooved region; (C) LRMed plate after machining; (D) machined SENB specimen (20 mm wide \& $10 \mathrm{~mm}$ thick) with triangular LRMed region at the centre; (E)

LRMed and machined plate from which Charpy impact samples (shown in the inset) were extracted.

\subsection{Fabrication \& testing of Single edge notched bend (SENB) and Charpy impact specimens}

The substrate used for the fabrication of SENB and Charpy impact specimens was a stainless steel (AISI 316L SS) block (150 mm x $150 \mathrm{~mm}$ x $25 \mathrm{~mm}$ ) with a machined $12 \mathrm{~mm}$ deep V-grooved region at its center, as shown in Fig. 1A. The V-grooved region was filled with IN-625 by LRM, involving laser cladding along $150 \mathrm{~mm}$ length of the " $\mathrm{V}$ " groove region. The direction of laser cladding was changed by $180^{\circ}$ between adjacent clad tracks (refer Fig. 1B). The laser-deposited block was subsequently machined to extract SENB and Charpy impact test specimens (as per ASTM E-1820 and E-23 respectively) [16,17]. Figure 1 presents various stages involved in specimen preparation. Standard notches were provided by EDM wire cut machining in such a way that tip of the machined notches fell in LRMed region so as to facilitate initiation and propagation of fracture from the LRMed region of the specimens (refer Figs. 1D and 1E). The present fabrication methodology not only eliminates lengthy process of LRM of full SENB/Charpy specimens but also serves the very purpose of evaluation of fracture toughness (crack tip opening displacement)/impact toughness of LRMed structure of IN- 625. A similar specimen fabrication approach has been reported by Corwin et al [18]. In order to determine improvement in toughness due to stress relieving and micro-structural improvement, three SENB specimens were subjected to a heat-treatment involving heating to $950{ }^{\circ} \mathrm{C}$ for one hour followed by oil quenching to obtain optimum mechanical properties [13]. In the subsequent text, "as LRMed" and "heat treated LRMed" specimens are referred as "as-LRM" and "LRM-HT", respectively. Prior to CTOD 
testing, LRMed SENB specimens (4 "as-LRMed" and 3 "LRM-HT") were pre-cracked to generate 1.5-1.8 mm long fatigue cracks $\left(\mathrm{a}_{0} / \mathrm{W}=0.55-0.65\right)$ where $\mathrm{a}_{0}$ is the initial crack length and $\mathrm{W}$ is the total width of the specimen. The specimens were tested using a $50 \mathrm{kN}$ servo-hydraulic machine at room temperature under displacement control with crack opening displacement (COD) gauge, as per standard test procedure ASTM E1820 [16]. Figure 2A presents CTOD-tested SENB specimens with crack propagation in central LRMed zone. Figure 2B presents load - COD plots of four representative LRMed specimens. On the other hand, fourteen numbers of impact test specimens (refer inset in Fig. 1E) were prepared, out of which 8 were tested in as-LRMed condition while 6 were tested in the heat treated condition. Charpy impact tests were carried out at room temperature using an instrumented impact testing machine as per ASTM E23.

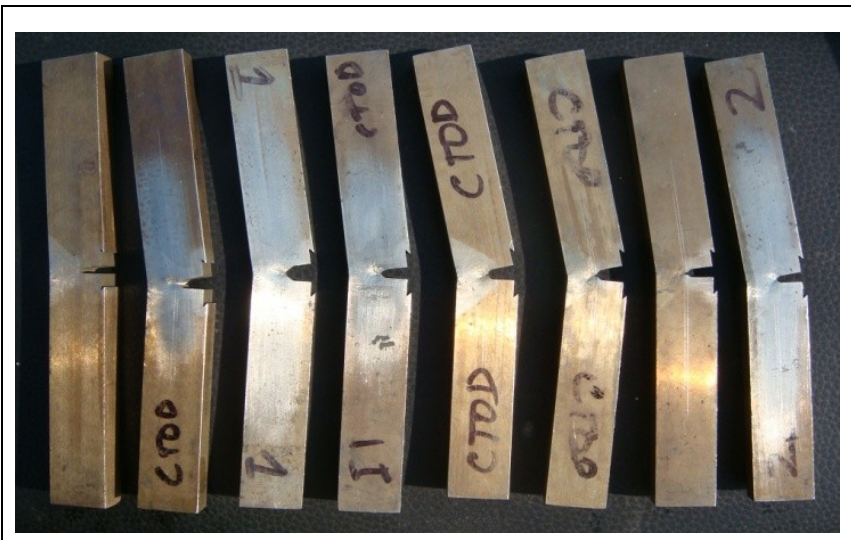

(A)

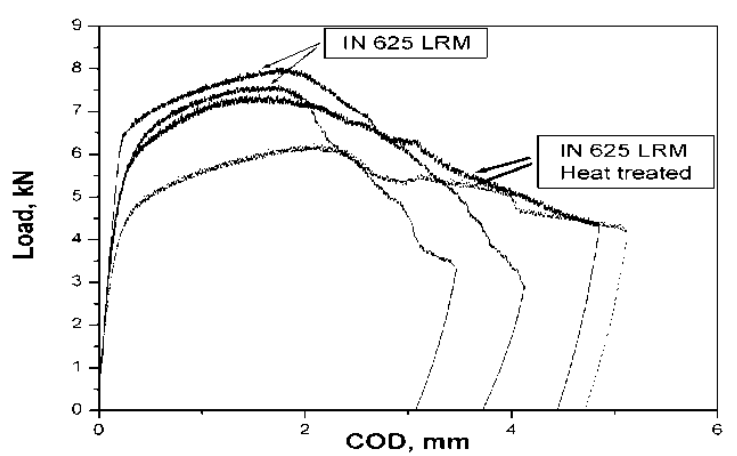

(B)

Figure 2: (A): CTOD-tested SENB specimens with different initial a/W; (B) CTOD test data.

\subsection{Results and discussion}

\section{1 : Crack tip opening displacement (CTOD) testing}

Load vs. COD plots of LRMed SENB specimens (as-LRM and LRM+HT) exhibited fully ductile fracture without any pop-in behavior, as shown in Fig. 2B. Therefore, the value of $\delta_{\mathrm{m}}$ (critical CTOD at maximum force plateau for fully plastic behavior) was calculated for all the specimens. CTOD $\left(\delta_{\mathrm{m}}\right)$ value of "as-LRM" specimens were found to be in the range of 0.28- $0.4 \mathrm{~mm}$ while for"LRM-HT" specimens the value of $\delta_{\mathrm{m}}$ was in the range of $0.34-0.54 \mathrm{~mm}$. Figure 3 presents magnified view of the crack path in two CTOD-tested SENB specimens. Absence of any crack tip blunting after pre-crack is indicative of dominant elastic stress (plane strain) conditions prevailing due to adequate thickness constraint. There are no published reports on CTOD fracture toughness measurement of laser-fabricated structures of IN-625 alloy. However, there are two reports of CTOD fracture toughness of IN-625 weld metal (WM). Cam et al. [19] reported that CTOD fracture toughness of WM of laser welded IN-625 sheet was in the range of 0.48-0.54 mm whereas Yeni et al [20] reported relatively higher value of CTOD $\left(\delta_{5 \max }=0.53-0.88 \mathrm{~mm}\right)$ for similar laser $\mathrm{WM}$ of IN-625. The values of $\delta_{5 \max }$ for the IN-625 in the wrought form are about $1.03-1.16 \mathrm{~mm}$ [19]. The lower CTOD fracture toughness obtained in the present investigation is attributed to inclusions formed as a result of atmospheric contamination. Also the thickness of the specimens used in the present study was $10 \mathrm{~mm}$ whereas the reported results were obtained from $3.2 \mathrm{~mm}$ thick laser welded sheet specimens. Specimen thickness strongly influences its fracture toughness as mode of fracture undergoes a transition from plane stress to plane strain condition (with associated increase in constraint at the crack tip) with increase in thickness. This explains relatively lower CTOD values obtained in the present study with respect to those reported in literature. 


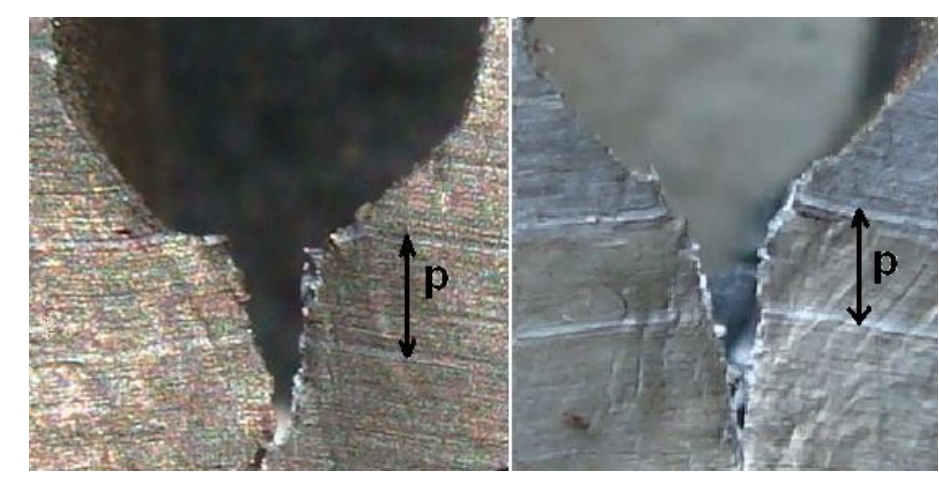

Figure 3: Magnified view CTOD-tested SENB specimens showing the nature of crack propagation in the LRMed SENB specimens. ("p": extent of pre-crack from the end of machine notch).

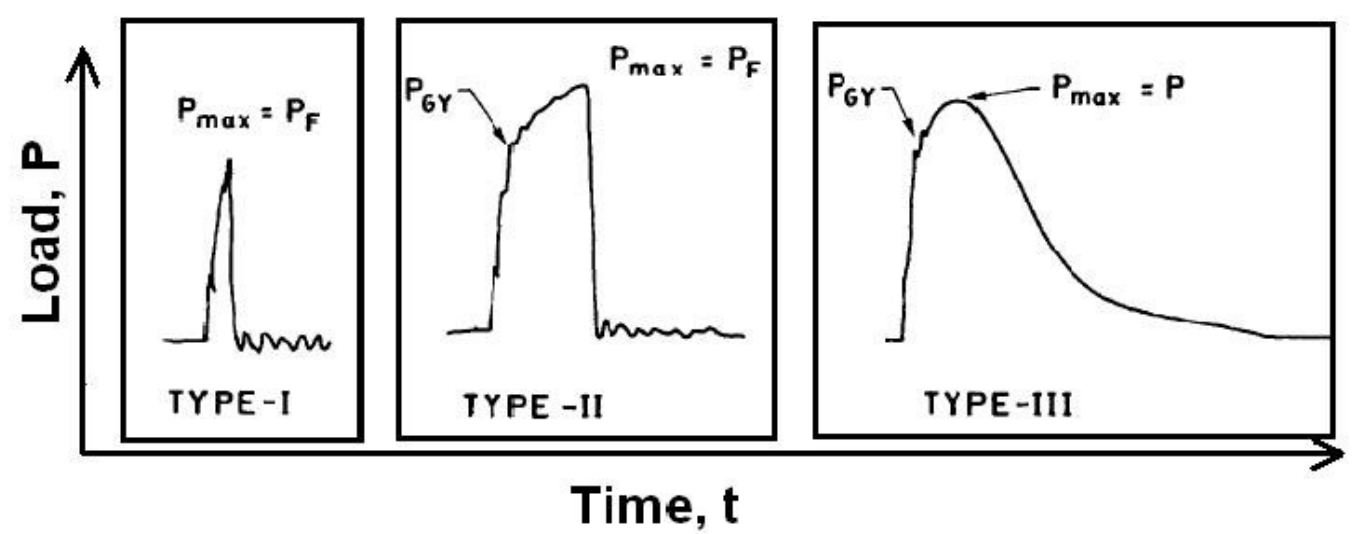

Figure 4: Different kinds of load-time (P-t) traces obtained from instrumented Charpy impact tests. $\left(\mathrm{P}_{\mathrm{GY}}\right.$ : general yield load; $\mathrm{P}_{\max }$ : maximum load; $\mathrm{P}_{\mathrm{F}}$ : fracture load) $\quad[21,22]$.

\subsection{Dynamic fracture behavior of LRMed Inconel 625 Charpy specimens}

The load-time (P-t) trace of instrumented Charpy impact specimens provide information concerning general yield load $\left(\mathrm{P}_{\mathrm{GY}}\right)$, maximum load $\left(\mathrm{P}_{\max }\right)$ and fracture load $\left(\mathrm{P}_{\mathrm{F}}\right)$ and also the time corresponding to onset of brittle fracture [22]. Depending on mechanical property characteristics of the specimen, load-time trace of instrumented impact test can be categorized into three types viz. I, II and III, as shown in Fig. 4 [21]. Type I behavior, representing brittle or fast running fracture, is characterized by sudden drop in load occurring at general yield indicating linear-elastic material behavior. On the other hand, type II behavior involves fast fracture occurring after general yielding at $\left(\mathrm{P}_{\mathrm{F}}=\mathrm{P}_{\max }\right)$. In contrast, type III plot represents complete ductile fracture with no sudden drop in load. Load-time plot of this kind is characterized by initial drop in load followed by long tail representing arrest of fast fracture after some propagation. Instrumented Charpy impact tested LRMed IN-625 specimens exhibited type III P-t traces, which are indicative of ductile fracture. In order to determine fracture energy, load-time traces obtained from instrumented impact tests, were subsequently converted into load-displacement (P-d) traces. Figure 5A presents a typical P-d trace of instrumented impact test showing energy consumed in crack initiation $\left(\mathrm{E}_{\mathrm{I}}\right)$ and its propagation $\left(\mathrm{E}_{\mathrm{P}}\right)$ [22]. Electronically acquired data obtained through oscilloscope (by integrating $\mathrm{P}-\mathrm{d}$ trace), was validated by comparing total fracture energy $\left(\mathrm{E}_{\mathrm{T}}\right)$ with that provided by analog read out of the machine. The difference between these two energy values was within $+/-2 \%$. Figure 5B presents P-d plots of "as-LRMed" and "LRM-HT" specimens of IN-625 specimens. It 
has been observed that heat treatment of LRMed structure brought about an increase in the fraction of initiation fracture energy $\left(\mathrm{E}_{\mathrm{I}} / \mathrm{E}_{\mathrm{T}}\right)$ from about $50 \%$ in "as-LRMed" condition to about $63 \%$ in heat treated condition. LRM-HT specimens recorded about 10-13\% higher Charpy impact energy over "as-LRM" specimens. Lateral expansion (LE) of "as-LRM" specimens was consistently in the range of 23-26 mils $(0.58-0.66 \mathrm{~mm})$ whereas "LRM-HT" specimens exhibited LE of 18- 30 mils $(0.46-0.76 \mathrm{~mm})$. Both kinds of impact tested specimens displayed flat fracture surfaces with small shear lips. Fractographic examination of impact tested specimens under scanning electron microscope (SEM) revealed dimpled fracture surfaces of "as-LRM" and "LRM-HT" specimens, indicating ductile nature of fracture, as shown in Fig. 6. It has been observed that the dimples were aligned along the length of columnar grains, indicating that the crack followed the growth direction of columnar grains. Lateral expansion measurements and fractographic examination are indicative of ductile nature of crack growth in LRMed Inconel-625 specimens under dynamic loading conditions, which is also evident from Type III load displacement curves (refer Fig. 5B).

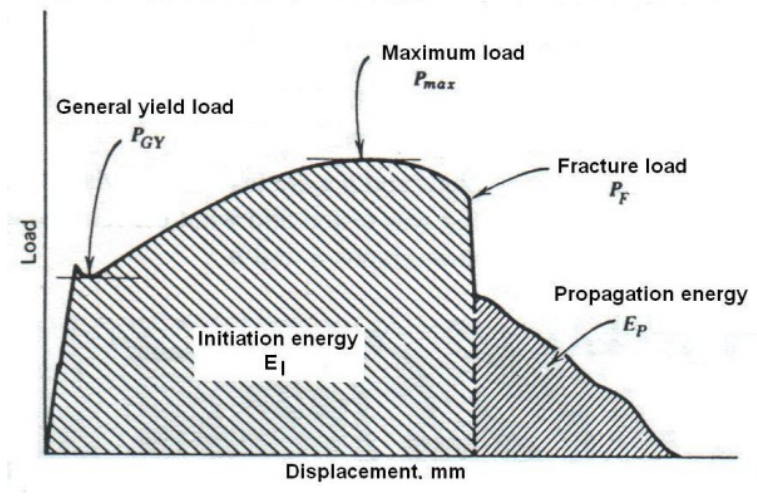

(A)

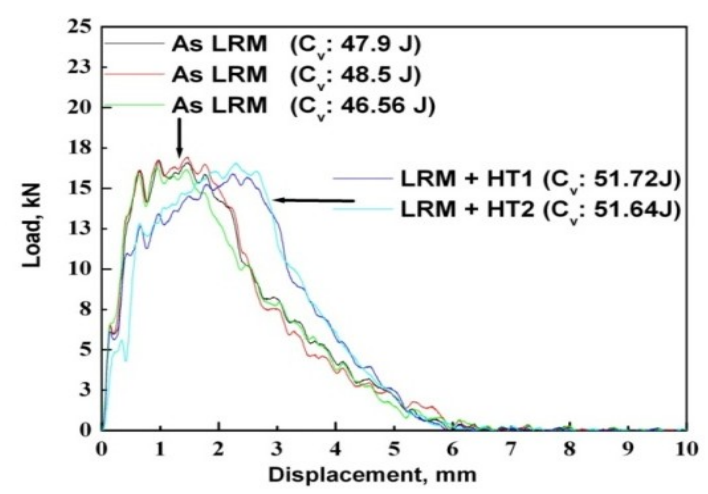

(B)

Figure 5: (A) Schematic of load-time trace from an instrumented impact test with details of various load points, energy consumed for crack initiation $\left(E_{I}\right)$ and propagation $\left(E_{P}\right)$ [22]. (B) Load versus displacement plots and corresponding CVN energy of specimens in the LRMed as well as LRM- HT condition.
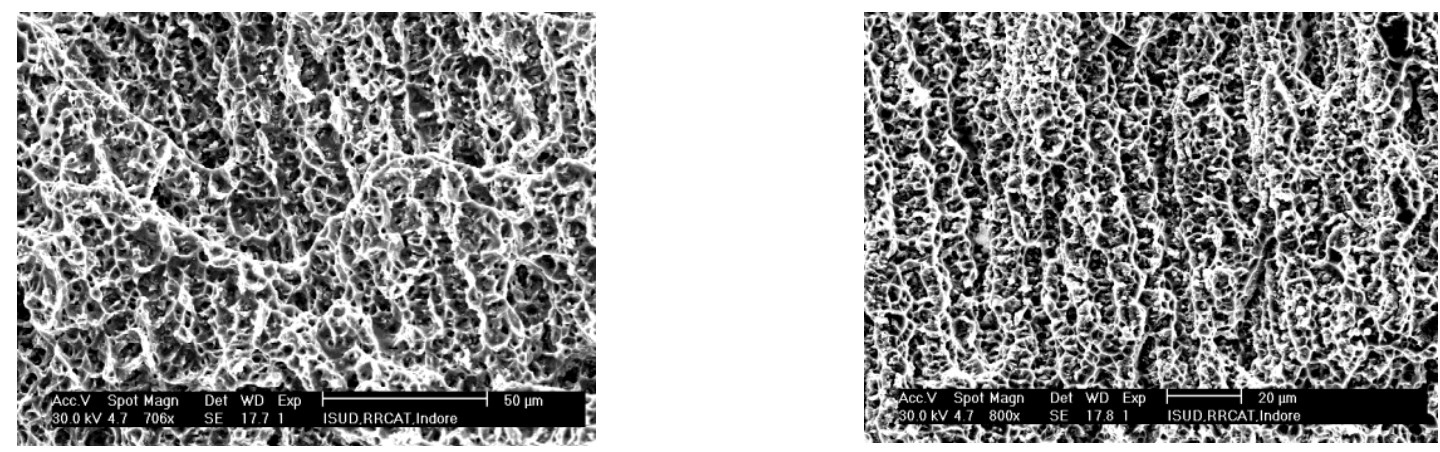

Figure 6: SEM fractographs of charpy impact tested (left) as-LRMed $\left(\mathrm{C}_{\mathrm{v}}: 48.5 \mathrm{~J}\right)$ and (right) LRM-HT $\left(\mathrm{C}_{\mathrm{v}}: 54 \mathrm{~J}\right)$ specimens. Crack propagation is from bottom to top.

\subsection{Estimation of fracture toughness parameters from Instrumented Charpy impact results}

The potential of using conventional Charpy-V notch test in determining the dynamic fracture toughness parameters like $\mathrm{K}_{\mathrm{ID}}, \mathrm{J}_{\mathrm{Id}}$ and $\delta_{\text {id }}$ has been reported earlier [22-25]. Although pre-cracked Charpy specimens are recommended for evaluation of dynamic fracture toughness parameters, an 
attempt is made to estimate fracture toughness parameters from un-precracked standard Charpy specimens. P-d traces have been analyzed using a J-integral or CTOD procedure assuming crack initiation at the maximum load [26, 27]. It may be noted that fairly accurate estimate of dynamic yield strength of the material can be made from general yield load, $\mathrm{P}_{\mathrm{GY}}$ determined from the P-d plot of instrumented Charpy test $[28,29]$. The dynamic yield strength $\left(\boldsymbol{\sigma}_{\mathrm{Yd}}\right)$ can be estimated from general yield load $\left(\mathrm{P}_{\mathrm{GY}}\right)$ using the following relation [29]:

$$
\boldsymbol{\sigma}_{\mathrm{Yd}}(\mathrm{MPa})=46.7 \mathrm{P}_{\mathrm{GY}}(\mathrm{kN})
$$

According to empirical relation proposed by Sumpter and Sorem $[30,31]$ for shallow cracks $(\mathrm{a} / \mathrm{W}=$ 0.15-0.3), plastic part of CTOD $\left(\delta_{\mathrm{pl}}\right)=\mathrm{r}_{\mathrm{pl}}$, where $\mathrm{r}$ : plastic rotation factor $(\sim 0.2)$ and $\mathrm{d}_{\mathrm{pl}}$ : plastic displacement part of P-d trace. Total CTOD at initiation $\left(\delta_{\mathrm{iD}}\right)$ is given as the sum of elastic and plastic parts as given by the following equation $\left(\boldsymbol{\delta}_{\mathbf{i}}=\boldsymbol{\delta}_{\mathbf{e}}+\boldsymbol{\delta}_{\mathrm{pl}}\right)$ [31].

$$
\delta_{\mathrm{iD}}=\left[K^{2} \cdot\left(1-v^{2}\right) /\left(2 \cdot \sigma_{\mathrm{Yd}} \cdot \mathrm{E}\right)\right]+\delta_{\mathrm{pl}}
$$

where $\mathrm{K}=$ 4.67. $\mathrm{P}_{\mathrm{F}}\left(\mathrm{P}_{\mathrm{F}}\right.$ : load at crack initiation/maximum load); $v$ : poisson's ratio and E: Elastic modulus. Based on the empirical relation proposed by Sumpter [30] for a specimen with $\mathrm{a} / \mathrm{W}=0.2$, the value of initiation fracture toughness $\left(\mathrm{J}_{\mathrm{i}}\right)$ is given by the following Eq.3:

$$
\mathbf{J}_{\mathbf{i}}=\mathbf{1 . 4 5 .} E_{l} /(\mathbf{B} . \mathbf{b})
$$

where $E_{I}$ : Energy absorbed up to crack initiation; B: specimen thickness; b: $\left(\mathrm{W}-\mathrm{a}_{0}\right)=8 \mathrm{~mm}$ for full size CVN specimen. However for materials exhibiting type II or type III load time traces and elastic plastic procedure has to be applied. Usually such traces have been analyzed using J-integral procedure assuming crack initiation occurs at maximum load [26, 27]. Ghoneim and Hammad [33] proposed that fracture initiation occurs at a load equal to $\left(\mathrm{P}_{\max }+\mathrm{P}_{\mathrm{GY}}\right) / 2$, while Norris [34] based on a comparison of finite element results with experimental data, reported that the time to crack initiation, $\mathrm{t}_{\mathrm{i}}$, equals $40 \%$ of the time to reach the maximum load, $\mathrm{t}_{\max }$. Based on these critical considerations the value of $E_{I}$ in the Eqn. 4 is assumed as the energy absorbed up to the maximum load $\left(\mathrm{P}_{\max }\right)$ and $\left(\mathrm{P}_{\max }+\mathrm{P}_{\mathrm{GY}}\right) / 2$ in the load displacement traces of the Charpy impact tests $[26,27,33]$. Dynamic plane strain fracture toughness $\left(\mathrm{K}_{\mathrm{Id}}\right)$ has been estimated from Charpy energy $\left(\mathrm{C}_{\mathrm{V}}\right)$ by various researchers [22,32]. Equation 4, given below is one of the most successful correlations applicable over a wide range of $\mathrm{C}_{\mathrm{V}}(3-95 \mathrm{~J})$ and yield strength (270 to $\left.815 \mathrm{MPa}\right)$ [32].

$$
K_{\text {Id }}\left(C_{V}\right)=15.5\left(C_{V}\right)^{0.375}
$$

Table 3 presents dynamic fracture toughness parameters estimated from above mentioned empirical relations. It has been noted that the experimentally determined CTOD $\left(\delta_{\mathrm{m}}\right)$ values were in close agreement with those estimated from Charpy impact results. J-integral fracture toughness, estimated from Charpy impact results, assuming crack initiation at maximum load [26, 27], are higher with respect to experimentally evaluated results reported for LRMed IN-625 [8]. Whereas it is seen that the estimated $\mathrm{J}_{\mathrm{iD}}$, values from $\mathrm{C}_{\mathrm{V}}$ results are close to experimentally evaluated fracture 
toughness values [8] considering the relations proposed by Ghoneim and Hammad [33] for both the as-LRMed and LRM-HT specimens. From these calculations it can be inferred that the assumption of initiation of crack at the load value of $\left(\mathrm{P}_{\max }+\mathrm{P}_{\mathrm{GY}}\right) / 2$ [33] results in better estimation of $\mathrm{J}$ integral fracture toughness values in the present case.

\begin{tabular}{|c|c|c|c|}
\hline $\begin{array}{l}\text { Toughness } \\
\text { parameters }\end{array}$ & As-LRMed & LRM - HT & $\begin{array}{l}\text { Experimentally } \\
\text { measured }\end{array}$ \\
\hline $\operatorname{CTOD}\left(\delta_{\mathrm{i}}\right) \quad(\mathrm{mm})$ & $0.2-0.24 \quad[30,31]$ & $0.36-0.37[30,31]$ & $\left(\delta_{\mathrm{m}}\right): 0.28-0.54$ \\
\hline $\mathrm{J}_{\mathrm{iD}} \quad\left(\mathrm{kJ} / \mathrm{m}^{2}\right)$ & $\begin{array}{cc}205-326 & {[26,27]} \\
188-200 & {[33]} \\
\end{array}$ & $\begin{array}{cc}480-500 & {[26,27]} \\
234-276 & {[33]} \\
\end{array}$ & $\left(\mathrm{J}_{1 \mathrm{c}}\right): 194-254[8]$ \\
\hline $\mathrm{K}_{\mathrm{Id}}\left(\mathrm{C}_{\mathrm{V}}\right)(\mathrm{MPa} \sqrt{ } \mathrm{m})$ & $66.14-66.7$ & 68-69.2MPa $\sqrt{\mathrm{m}}$ & Not available \\
\hline
\end{tabular}

\section{Conclusions}

Present study has demonstrated that laser rapid manufactured structures of Inconel-625 are associated with fairly good fracture toughness. Laser rapid manufactured specimens, in as-laser rapid manufactured and heat treated conditions (at $950{ }^{\circ} \mathrm{C}$ ) exhibited stable crack growth behavior during CTOD test without any pop-in. CTOD fracture toughness $\left(\delta_{\mathrm{m}}\right)$ was found to be in the range of $0.28-0.54 \mathrm{~mm}$, which is relatively lower than those reported for IN-625 weld metal. Laser rapid manufactured Charpy specimens displayed type III load-time behavior under dynamic loading conditions indicating ductile nature of fracture. Stress relieving heat treatment brought about a modest increase in impact energy of laser rapid manufactured specimens from 48-50 J to 50-54 J, with initiation fracture energy registering a rise from about $50 \%$ (in as-laser rapid manufactured condition) to about $60 \%$ (in heat treated condition). Fracture toughness parameters, viz. CTOD- $\delta_{\mathrm{i}}$ and $\mathrm{J}_{\mathrm{iD}}$ estimated from instrumented impact test results of un-precracked Charpy specimens, were in close agreement with the experimentally evaluated data considering appropriate empirical relations proposed in the open literature.

\section{Acknowledgements}

Authors thankfully acknowledge the support provided by Dr. C. P. Paul, Shri Harish Kumar, Shri T. Reghu, Shri C. H. Prem Singh, Shri C.S. Mandloi and Shri Ram Nihal Ram in conducting the experiments, preparation of specimens and useful technical discussions.

\section{References}

[1] http://www.sandia.gov/mst/technologies/net-shaping.html, last visited on Dec.18,2012.

[2] P.L. Blackwell and A. Wisbey, Laser-aided manufacturing technologies; their application to the near-net shape forming of a high-strength titanium alloy, J. Mater. Process. Technol. 170 (2005) 268-276.

[3] F. Wang, J. Mei, Xinhua Wu: Direct laser fabrication of Ti 6Al 4V/TiB, J. Mater. Process. Technol. 195 (2008) 321-326. 
[4] Robert P. Mugde, Nicholas R. Wald: Laser Engineered Net Shaping Advances Additive Manufacturing and Repair, WJ 86 (2007) 44-48.

[5] G P Dinda, A K Dasgupta, J Majumder: Laser aided direct metal deposition of Inconel 625 superalloy: Microstructural evolution and thermal stability, Mat. Sci. Eng.A, 509 (2009) 98-104.

[6] A. Pinkerton, W. Wang, L. Li: Component repair using laser direct metal deposition, Journal of Engineering Manufacture B, 222 (2008) 827-836.

[7] G. K. Lewis, E. Schlinenger: Practical consideration and capabilities for laser assisted direct metal deposition, Mater. Des. 21 (2000) 417-423.

[8] P Ganesh, R Kaul, CP Paul, P Tiwari, SK Rai, RC Prasad, LM Kukreja, Fatigue and fracture toughness characteristics of laser rapid manufactured Inconel 625 structures, Materials Science and Engineering: A 527 (29-30) (2010), 7490-7497.

[9] C.P. Paul, P. Ganesh, S.K. Mishra, P. Bhargava, J. Negi, A.K. Nath, Investigating laser rapid manufacturing for Inconel-625 components, Optics \& Laser Technol., 39 (2007) 800-805.

[10] L. Xue, M.U. Islam, Free-form laser consolidation for producing metallurgically sound and functional components, J. Laser Appl. 12 (4) (2000) 160-165.

[11] Y. Xue, A. Pascu, M.F. Horstemeyer, L. Wang, P.T. Wang: Microporosity effects on cyclic plasticity and fatigue of LENS-processed steel, Acta Mater. 58(11) (2010) 4029-4038.

[12] A. Theriault, L. Xue, J. R. Dryden: Fatigue behavior of laser consolidated IN-625 at room and elevated temperatures, Mater. Sci. Eng. A 516 (2009) 217-225.

[13] http://www.specialmetals.com/documents/Inconel\%20alloy\%20625.pdf visited on Dec. 18, 2012. Special Metals Corporation Products, INCONEL® alloy 625.

[14] A.K. Nath, L. Abhinandan, P. Choudhary, Operational characteristics of a pulse-sustained dc-excited transverse-flow $\mathrm{CW} \mathrm{CO}$ laser of 5-kW output power, Optical Engineering, 33 (6) (1994) 1889-1893.

[15] J. Khare, R. Sridhar, C.P. Paul, T. Reghu, A. K. Nath, Operational characteristics and power scaling of a transverse flow transversely excited CW CO2 laser, Pramana, 60(1), (2003) 99-107.

[16] Standard test method for measurement of fracture toughness, ASTM E 1820, Annual hand book of ASTM Standards, 03.01, (ASTM international, west Conshohoken, PA, USA, 2001).

[17] Standard Test Methods for Notched Bar Impact Testing of Metallic Materials, ASTM E 23-02, ASTM International, West Conshohocken, PA 19428-2959, United States.

[18] W. R. Corwin, S. T. Rosinksi, Eric Van Wallw: Eds., Small specimen test techniques, ASTM STP 1329, (ASTM International, West Conshohocken, PA, United States, 1998) pp. 411, 420, 436, 484, 523-538.

[19] G. Cam, J. F. dos Santos, M. Kocak: Properties of laser beam welded superalloys Inconel 625 and 718, Proc. of European conference on laser treatment of materials, ECLAT, B. L. Mordike, Ed. (Sept. 22-23, Hanover, Germany, 1998) pp 333-338.

[20] C. Yeni, M. Kocak: Fracture toughness analysis of laser-beam-welded superalloys Inconel 718 and 625, Fatigue Fract. Eng. Mater. Struct., 29(7) (2006) 546-557.

[21] Aniruddha Moitra: "Studies on Ductile-Brittle Transition of 9Cr-1Mo Steels", PhD Thesis, Institute of Technology, Banaras Hindu University, Varanasi, India, 2003.

[22] R. W. Hertzberg: Deformation and fracture mechanics of engineering materials, Fourth Edition, (John Wiley and Sons, Inc., New York 1996) p 400, 398.

[23] P. R. Sreenivasan, A. Moitra, S. K. Ray, S. L. Mannan: Dynamic fracture toughness properties of a $9 \mathrm{Cr}-1 \mathrm{Mo}$ weld from instrumented impact and drop-weight tests, Int. J. Pres. Ves. \& Piping 69 (1996) 149-159.

[24] J.P. Tronskar, M.A. Mannan, M.O. Lai: Measurement of fracture initiation toughness and crack resistance in instrumented Charpy impact testing, Engineering Fracture Mechanics 69 (2002) 321-338. 
[25] K. Angamuthu, B. Guha, D.R.G. Achar: Investigation of dynamic fracture toughness $\left(\mathrm{J}_{\mathrm{Id}}\right)$ behavior of strength mis-matched Q \& T steel weldments using instrumented Charpy impact testing, Engineering Fracture Mechanics 64 (1999) 417-432.

[26] K.G. Samul, P.R. Sreenivasan, S.K. Ray, P. Roriguez: Evaluation of aging-induced embrittlement in an austenitic stainless steel by instrumented impact testing, J. Nucl. Mater. 150 (1987) 78-84.

[27] K. R. Iyer, R. B. Miclot: Instrumented charpy testing for determination of the J-Integral, Instrumented impact testing, ASTM STP 563 (1974) pp. 146-165.

[28] W. L. Server: General yielding of Charpy V-notch and pre-cracked Charpy specimens, J Eng. Mater. Technol., Trans. ASME 100 (1978) 183-188.

[29] W. L. Server: Impact three point bent testing for notched and pre-cracked specimens, Journal of Testing and Evaluation 6 (1978) 29-34.

[30] J. D. G. Sumpter: $J_{c}$ determination of shallow notch welded bend specimen, Fatigue Fract. Eng. Mater. Struct. 10 (1987) 479-493.

[31] W. A. Sorem, R. H. Jr. Dodds, S. T. Rolfe: Effects of crack depth on elastic-plastic fracture toughness, Int. J. Fract. 47 (1991) 105-126.

[32] R. Roberts, C. Newton: Interpretive report on small-scale test correlation with $\mathrm{K}_{\mathrm{IC}}$ data, Welding Research Council Bull. 265, February (1981).

[33] M. M. Ghoneim, \& F. H. Hammad, Instrumented impact testing of an irradiated 20MnMoNi55 PVS weld material, J. Nucl. Mater., 186 (1992) 196-202.

[34] D. M. Norris Jr, Computer simulation of the Charpy V-notch test, Eng. Fract. Mech, 11 (1979) 261-74. 